\title{
Development of Learning Systems for Children to Promote Self-Directed Choosing of Learning Tasks
}

Yoshihiro Kawano, Tokyo University of Information Sciences, Japan

Yuka Kawano, Candy, Japan

\begin{abstract}
In this study, a learning-data collection system to acquire the data regarding developmental stages and learning activities has been developed for the purpose of self-directed choosing of learning tasks by children. The skills necessary for the children to choose their own learning tasks are categorized into three segments-“computational thinking," "ICT literacy," and "social perspective"- that correspond to learning the various activities that the authors promote. These learning activities are "programming classroom," "IT advisement session," and "children's city." This study proposes a system design of the learning-data collection system. The learning-data are collected in the programming classrooms. The research question of this study is to find out how the learning frequency in programming education for children affects the depth of reflection and the differences in the quality of learning. As a result of analyzed learning-data, it was confirmed that the more frequent the learning, the deeper reflection was possible to promote more self-directed learning.
\end{abstract}

\section{KEYWORDS}

Community Activities, Developmental Stages, Learning Analytics, Learning Support System, Learning-Data Collection System, Programming Education, Self-Directed Learning

\section{INTRODUCTION}

The United Nations estimates that the world population will exceed 10 billion by 2055 (United Nations, 2017). There are many challenges such as global climate change, food, water and energy issues, poverty and educational disparities, unemployment, and lack of innovation. Achieving the United Nations Sustainable Development Goals by 2030 will require all of humanity to work together to determine what each of us can do to contribute to the goal. To sow the seeds of possibility and nurture the independence of the children who will carry the world 20-30 years from now, is to be open to an extraordinary future of humanity.

Increasingly many countries around the world are teaching computer science, including programming, to children. In particular, Estonia and the United Kingdom were the first two countries to introduce it; gradually, algorithms and programming languages have been incorporated (MEXT, 
2015). In Japan, programming education in elementary schools has been earnestly started from April 2020, and many programming classes have been started in many places in Japan (MEXT, 2016). In programming education, cross-sectional and comprehensive inquiry-based learning is expected to foster logical thinking and facilitate addressing social issues through programming (Shibuya, 2018). The significance of this course is not only to learn programming languages, but also to experience the logical flow of "problem discovery," "extraction and organization of issues," and "implementation of solutions" to the various problems we face in modern society.

The authors have been working on and discussing the business plan and operation of programming classes for children since 2016 (Kawano \& Kawano, 2018). Although children have a variety of learning opportunities, it is not clear how they contribute to the choice of their own learning tasks or which tasks are suitable for them based on their disposition and interests. In this study, the authors propose a learning-data collection system that collects data regarding the developmental stages and learning activities of children, in order to investigate the behavioral traits and interests that contribute to their independent choice of learning tasks. Accordingly, the children's learning records are collected in the programming classroom and analyzed. After each class, the students are expected to record their impressions, achievements, and expectations for the next class.

This paper is organized in seven sections, including INTRODUCTION. In BACKGROUND below, related research on children's independence, community activities, and programming education are introduced, and the position of this study is presented. MAIN FOCUS OF THE ARTICLE clarifies the research question and provides a survey policy to achieve the goal. In SELF-DIRECTED LEARNING FOR CHILDREN, the authors indicate skills required for self-directed learning and learning activities corresponding the skills. In LEARNING SYSTEM FOR CHILDREN, specific designs for a learning-data collection system for children, including system requirements, database (DB) and API designs are provided. In LEARNING ANALYTICS, the authors analyze the achievement of the research question based on the reflection questionnaire after the learning activity. Finally, in CONCLUSION, the accomplishments of this study and prospects are discussed.

\section{BACKGROUND}

With respect to the learning process of children, a study on community cooperation for the welfare of the community to foster the independence of children (Ushiroyama, 2008) and a study on the necessity of various learning opportunities for children (Tamura, 2017) have been published. With regard to the development of children's autonomy, the book, "The 7 Habits of Highly Effective People" that promotes a philosophy of life that takes a long-term view, has been introduced to the "special activities" of elementary schools (Covey, 1989). Further, there is also a case study found regarding the autonomous activities of children (Takahashi, 2010).

Furthermore, with respect to programming education, in light of the compulsory programming education in elementary schools in 2020, the following are reported: a case study on programming from the perspective of manufacturing with robotic control (Matsuda, 2018), a case study on the creation of teaching materials and practical education in elementary schools from the perspective of computational thinking (Toyoda, 2017), a workshop report on cooperative work using visual programming tools, and a survey of issues for promoting programming education in elementary schools. However, there are no studies that discuss the necessity of ICT literacy and social perspective, in addition to computational thinking, to determine the scopes of social issues where children can contribute autonomously.

In this study, the authors classify and define the skills necessary for the children's learning into three categories: "Computational thinking", "ICT literacy", and "Social perspective", with the aim of facilitating the selection of proactive learning tasks that will prepare them to tackle social issues. Focusing on these three perspectives, the authors have developed a learning-data collection system that collects data regarding the developmental stages and learning activities of children. 


\section{MAIN FOCUS OF THE ARTICLE}

The research question of this study is to find out how the learning frequency in programming education for children affects the depth of reflection and the differences in the quality of learning. There are few case studies reported on the reflection of learning through continuous observation on programming education for children. If the answer to the research question can be clarified, appropriate feedback can be provided based on the learning frequency and the reflections. Concretely, when reflecting on each learning activity, the children are asked to answer in a questionnaire format whether they have enjoyed it, why they enjoyed it, did they do it, what they did, and what they want to do next time, and analyze the correlation between these factors. It is assumed that the learning frequency would have an impact on deep reflection that contributes to self-directed learning.

\section{SELF-DIRECTED LEARNING FOR CHILDREN}

\section{Skills Required to Promote Self-Directed Learning}

Children need to understand their own disposition and role in society in order to choose their own learning tasks. In order to know the interests of children and their potential contribution in relation to others, it is effective to expand their perspectives by experiential learning. The purpose of this study is to help children choose their own learning tasks, and the skills required for choosing their tasks are classified into three categories: "Computational thinking," "ICT literacy," and "Social perspective" (Figure 1) (Kawano \& Kawano, 2019; Kawano \& Kawano, 2020). "Computational thinking", "ICT literacy", and "Social perspective" are essential skills for self-directed learning, corresponding to "Creativity", "Cooperativeness", and "Sociality", respectively.

In order to identify the social-issue domains in which children can contribute, it has been determined that the following three skills are necessary: computational thinking to decompose and logically assemble elements to realize their own intentions; ICT literacy to handle computers, cooperate with others, and collect and disseminate information online; and social perspective to understand social systems and the flow of economic activities. In addition, the repeated implementation of these learning activities is expected to result in learning outputs that can address social issues.

\section{Activities Corresponding to the Required Skills}

Figure 1 shows the corresponding three activities of computational thinking, ICT literacy, and social perspective: programming classroom, IT Advisement Session, and the Children's city. The three activities that the authors promote corresponding to the aforementioned skills are described below.

\section{Programming Classroom}

The programming classroom is designed in collaboration with to provide practical education that captures the essence of computational thinking (Kawano \& Kawano, 2020). The classroom is an onsite programming school located in Ichikawa and Urayasu cities and offers three courses: weekly, biweekly, and monthly. Children are allowed to choose learning tasks flexibly according to their needs, and they may also consult their parents before making a choice.

During the introductory period, the students will work on task learning using Scratch, a visual programming tool developed by the MIT Media Lab. After the children have become familiar with programming to some extent, they are allowed to write their own design documents and work on free tasks. They may create simple games using Python, design their own role-playing games, control drones using JavaScript, and develop chatbots. The classroom policy promotes the independence of the children by allowing them to choose their own learning tasks, just as they are expected to do in university seminars and graduation research.

As a result of observing the behavior and interests of children in the classroom, the authors have found a wide variety of behavioral traits and interests: some children prefer to work silently on 


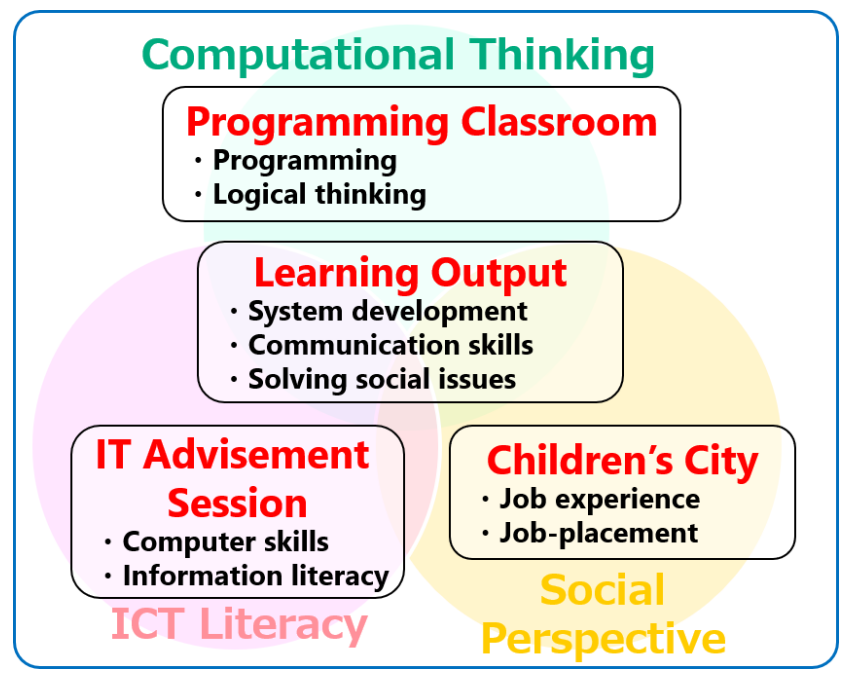

assigned tasks, some focus on drawing characters and backgrounds, some creative children find it easy to shift their interests, while others enjoy themselves by improving the games they create. During the introductory stage, it is important to cultivate the structure of the program and the concept of problem-solving while working on the given tasks. However, once their understanding advances to some extent, it is desirable to allow the children to work on free-thinking-based tasks that are in line with their behavioral traits and interests.

\section{IT Advisement Session}

The IT Advisement Session is an original component of the laboratory that teaches information technology to the children and facilitates programming experiences using PCs and tablets during community activities (Kawano \& Shingyoji, 2017).

Figure 2 shows the IT Advisement Session at the "Wakaba CBT Children's city" held at Uekusa Gakuen University in July 2018, where the authors broadcast a live video of the event to parents in

Figure 2. Picture of the IT Advisement Session

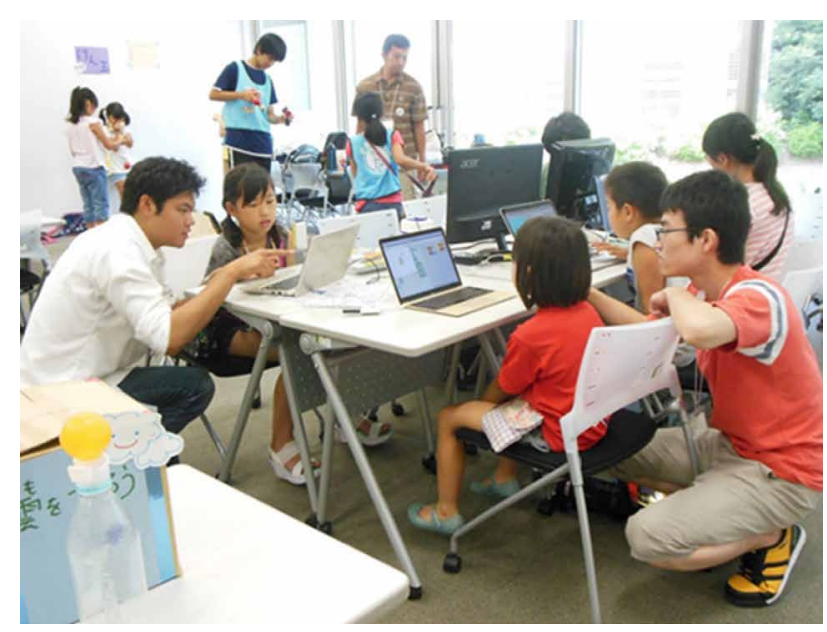


addition to providing a programming experience based on Scratch to the children. The IT Advisement Session activities are organized in conjunction with local activities, such as "Mitsuwadai Summer Festival" in Wakaba-ku, Chiba, Japan, "Shofusai" school festivals, and "Hanamigawa Danchi 100yen Shopping Street" in Hanamigawa-ku, Chiba, Japan (Kawano, 2014).

\section{Children's City}

The Children's city is a program that originated in Mini-Munich, Germany in 1979. It is hands-on event for children to autonomously plan and operate administrative institutions and shops that are available only to children (Kawano \& Kawano, 2020). Students will experience the discovery and development of social issues in community activities through their involvement with other elementaryschool-student participants and adults who support them. The author's laboratory has participated the event in Yotsukaido city, and Wakaba, Hanamigawa and Chuo ward in Chiba city.

Figure 3 shows a picture of the Children's city activity conducted in Yotsukaido. The event is held every year for two days during the summer vacation: one day at the Yoshioka Elementary School and at the Takanodai Park in Yotsukaido city on the next day. The Children's city activity is conducted in the festival area comprising Children's city a play park (outdoor learning), and a market accessible to everyone (space for food and beverage sales at the venue).

\section{LEARNING SYSTEM FOR CHILDREN}

\section{Design}

In this study, the authors have developed a learning support system for children based on the aforementioned philosophy. As shown in Figure 4, the level of achievement and satisfaction with respect to each activity is recorded and collected at the end of each learning activity corresponding to each skill, and the degree of similarity between the behavioral traits and interests of the children is calculated. While choosing a learning task, the children are trained to choose what they want to learn by presenting the tasks that other children have worked on that are highly similar to their own behavioral traits and interests. The tasks that other children have worked on that are highly similar to their own.

\section{Overview}

As mentioned in the above discussions, a learning-data collection system (henceforth, referred to as "collection system") has been developed as the first stage of the learning support system for children.

Figure 3. Picture of the Children's city activity

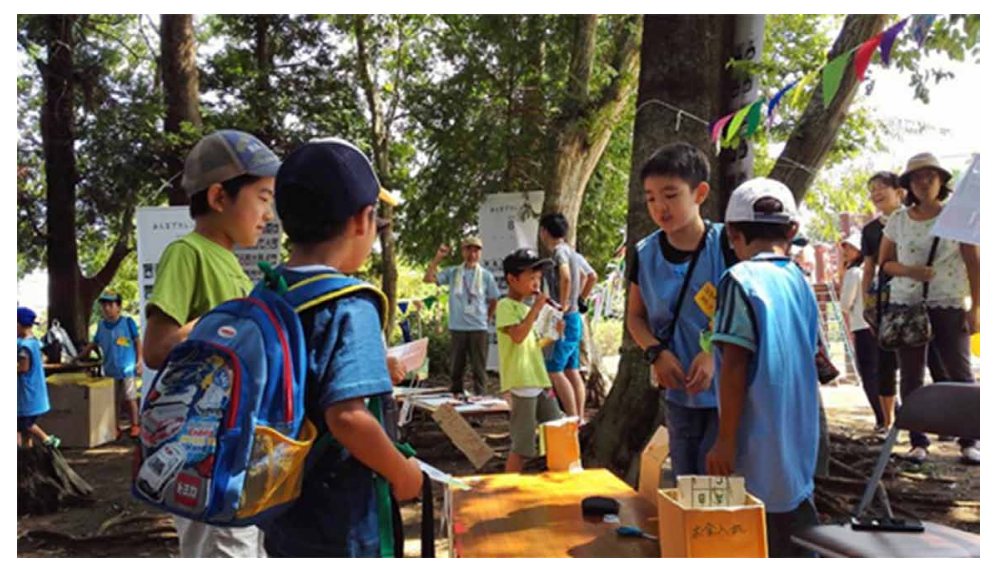




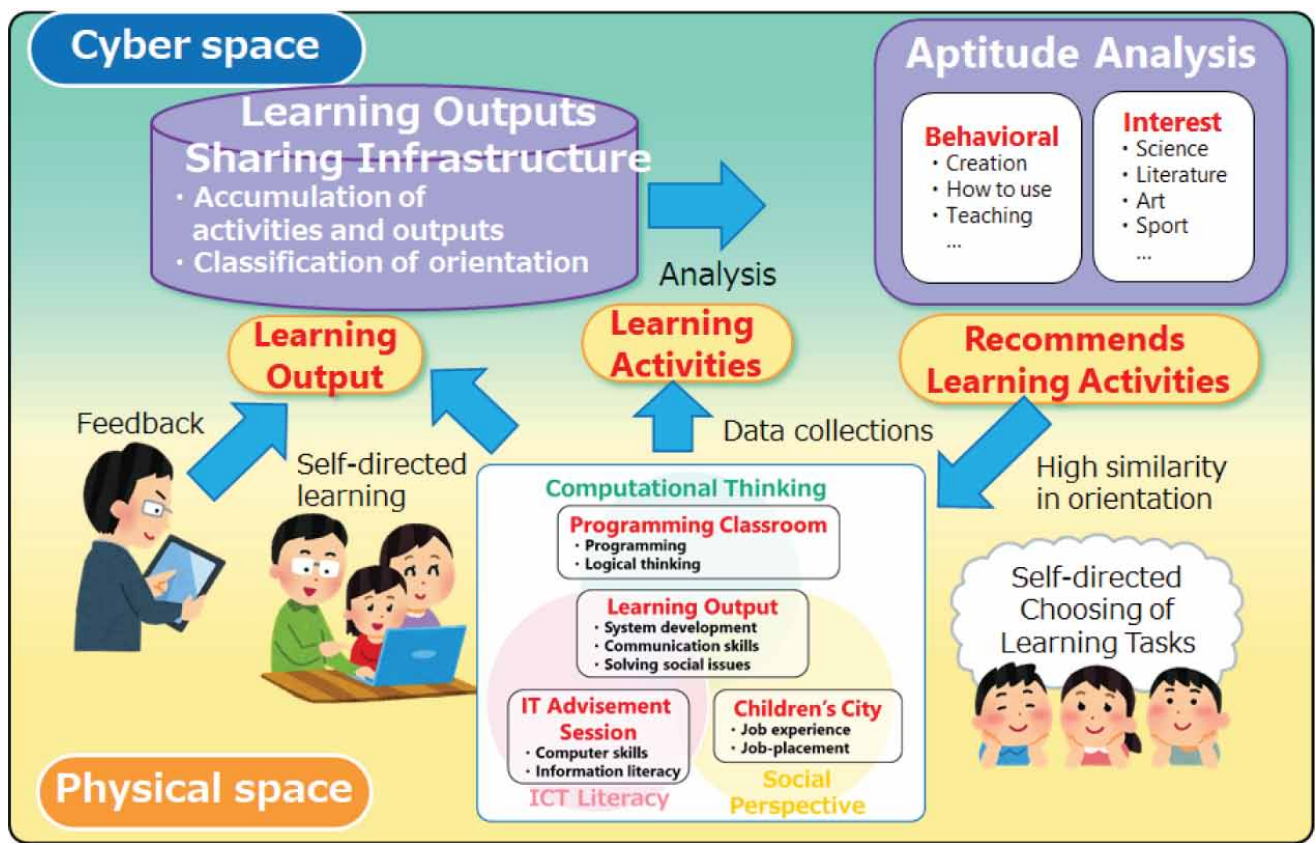

In this study, the learning-data such as type and difficulty of activities, achievement level and next target are collected through an input interface and a DB is used to record the data; this would facilitate reviewing the learning activities later. For the collection items, the depth of the content and the way of listening to the content can be adjusted according to the children's stage of growth, for example, the level of achievement and satisfaction with the activities. Concretely, the descriptions of the questions should be words learned in each grade level and sentence expressions that can be understood. For lower elementary school students, the questions should be related to the achievement of basic and task-related skills and emotions; for upper elementary school students, the questions should be related to self-affirmation and cooperation with others; and for junior high school students and later, the questions should be related to independent goal setting.

Therefore, the input interface of the collection system is developed as a simple questionnaire for children. The features and requirements of the collection system are the following:

1. The content and presentation of questions and choices can be dynamically switched according to the children's grades and learning activities.

2. Responses conveying the same meaning can be identified and categorized as the same response even if the content and presentation of the choices are different.

3. The questionnaire must be answered in as few steps as possible.

For feature 1 above, the depth of the content and the way of listening is adjusted according to the developmental stage of the target children. According to the Ministry of Education, Culture, Sports, Science and Technology (MEXT), "Characteristics of each stage of children's development and issues to focus on", in the early elementary grades of school, emphasis is placed on the judgement of right and wrong, developing a sense of normalcy in group life, and cultivating emotions (MEXT, 2009). In the later elementary grades, students need to develop an affirmative attitude, compassion for others, and 
awareness of their roles in the group. From junior high school, students are faced with the challenge of fostering the ability to live as a complete human being, to be oneself, and to lead an independent life. Based on the characteristics and issues of the developmental stages described above, the authors examine the data to be collected, including the data pertaining to the choice of the questions that are divided into three categories: early elementary grades, late elementary grades, and junior high school and later. In other words, nine questionnaire patterns are obtained for a combination of three developmental stages and three types of learning activities (programming classroom, IT Advisement Session, and the Children's city).

With respect to feature 2 mentioned above, the content and description of the questionnaire answers are different because the language comprehension and depth of thinking vary according to the child's developmental stage. Further, in order to calculate the degree of similarity between the behavioral traits and interests of children based large amount of data, it is desirable to be able to identify and categorize the answers that convey the same meaning between another activities or grades, even if the content and description of the choices are different. It is believed that the analysis of the children's aspirations based on a wide variety of data on learning activities will facilitate the recommendation of learning tasks that are in line with their aspirations and dispositions.

Finally, requirement 3 is based on the assumption that children are generally in a state of reduced concentration immediately after studying. Therefore, it is believed that it would be easier for children to answer the questionnaire in the shortest possible time; this would facilitate collection of more accurate data regarding their learning activities as well as reduction of workload of the children. In the Children's city learning activity, the work experience is completed every $30 \mathrm{~min}$, and immediately after that, children often queue up at the bank to receive their salary. The best timing to get the answers to the learning-data is just after receiving the salary at the bank. Since congestion at the bank interferes with the smooth progress of study activities, it is important to simplify the procedure of answering the collection system to shorten the waiting time.

\section{Frequency of Questionnaire Data Collection}

After the programming class, IT Advisement Session, and Children's city activities are conducted, the authors collect questions regarding the study content electronically from the children who wish to review the study content using mobile devices such as laptops and tablets. The timing of the collection of feedback in each learning activity is as follows:

- Programming class: At the end of each class (every 60 to $90 \mathrm{~min}$ ).

- IT Advisement Session: After experiencing each educational content such as information literacy dice game, business card making workshop, broadcaster experience at Children's city and Scratch programming (approximately every 5-30 min).

- Children's city: At the bank where the salary is paid after completion of the Children's city activity (approximately every $30 \mathrm{~min}$ ).

The collected data on learning activities are a review of the activities and expectations that are actually the responses to the following six questions: "Did you enjoy the activities, what did you enjoy, what are your goals, did you achieve the goals, what did you do, and what do you want to do next?" Since children are the subject of this study, a research protocol for experiments and investigations involving human subjects was submitted to the university's Ethics Review Committee for review and approval before the study and research were conducted. Informed consent was obtained from the parents of the children involved in the study after explaining the purpose of the study to them. Informed assent was obtained from the children who have been involved in this study. 


\section{Database Design}

The authors examine the DB design to ensure the features (1) and (2) of the collection system mentioned in the section, "Overview". Based on the discussion so far, the data structure required for this system is identified as follows.

Data structure of the system:

1. List of users:

a. Account Name, Password, and User Name

b. Account types: children, parent, and staff

c. Year of Admission (for the management of developmental stages)

d. Learning activities: Programming class, IT Advisement Session, and Children's city

e. Learning records

2. Questionnaire Information:

a. Questionnaire structure

b. Question and choice description

c. Developmental stages: early elementary grades, late elementary grades, junior high school and later

d. Answers to the questionnaire

The DB design (Entity-Relationship diagram) based on the above data structure is shown in Figure 5. As shown in Figure 5, the DB of this system consists of the following eight tables:

1. User information:

a. Users: basic user information

b. Categories: type of learning activities

c. Courses: learning content within a type

d. Course users: combination of user and course

2. Questionnaire Information:
a. Questionnaires: survey structure information
b. Questions: questionnaire items
c. Choices: survey choices
d. Grades: developmental stages

In the user information above, the user's account (children or parent type), the type of learning activity (programming class, IT Advisement Session, or Children's city), and the learning content selected by the user can be recorded. In the questionnaire information, the structural information pertaining to the questionnaire (combination of question and choice notation and choice identification number) and the actual question and choice notation of the questionnaire are recorded. This facilitates switching of the content and notation of questions and choices according to the child's grade and learning activities, as well as the identification of consent answers. Note that requirement 3 can be ensured by devising the implementation. Concretely, the authors implemented the functions of changing the question content according to the answer results and switching the question presentation without webpage transition.

\section{System Development}

The authors have developed a learning-data collection system that has been discussed in the preceding sections. To ensure features 1 and 2 of this system, a Web API is developed that can access the information regarding the questionnaire recorded in the DB. This API outputs a list of questions and choices in JSON format, with learning activities and developmental stages as the input parameters. In 
Figure 5. Entity-relationship diagram of the system

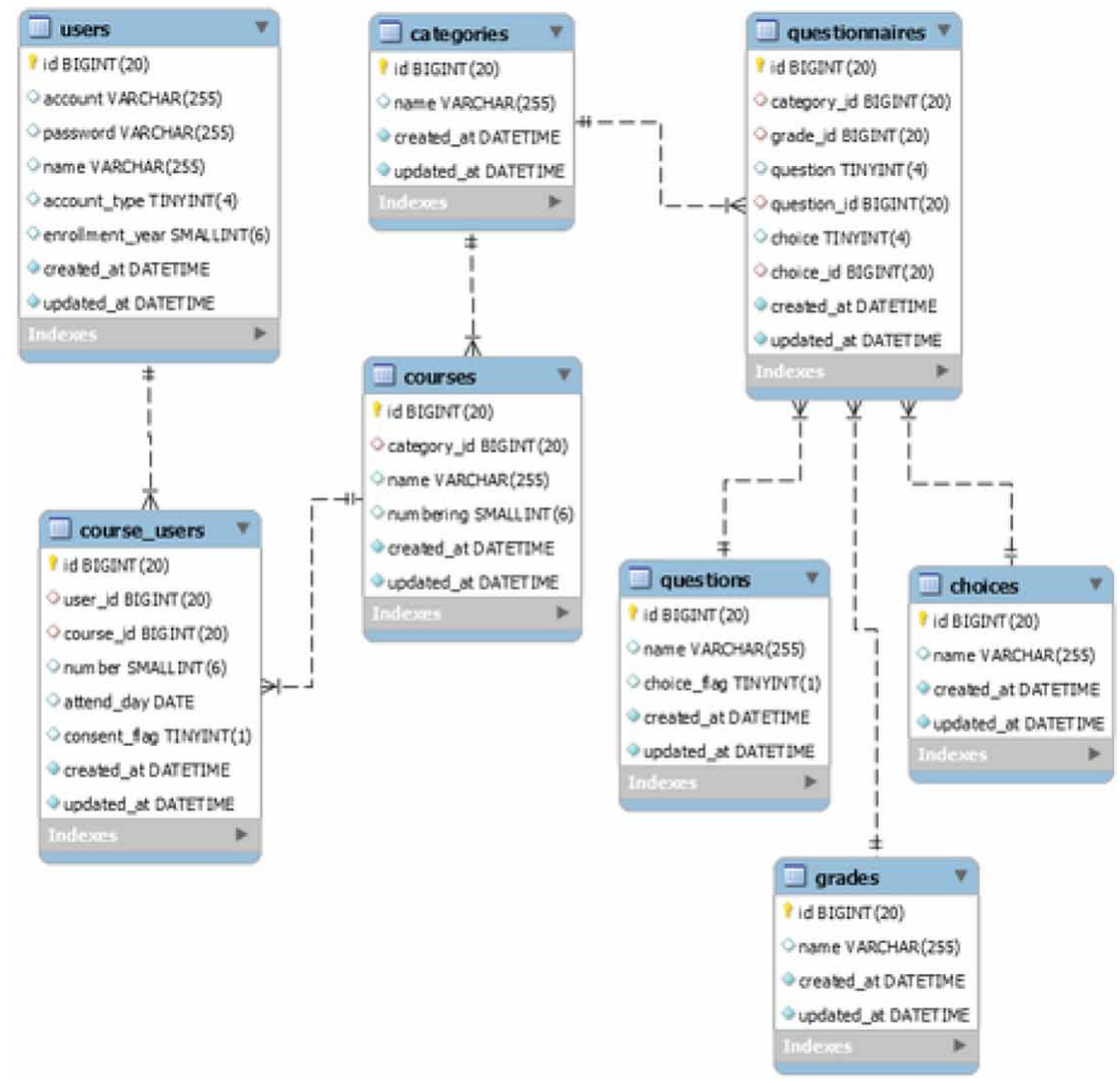

the Web API, the questions and choices of the questionnaire are output when programming is specified as the learning activity and elementary school is specified as the developmental stage, as the input parameters. In addition, when storing questionnaire response data, it is desirable to be able to store and analyze a large amount of response data at high speed in a simple manner. Therefore, MongoDB is adopted that is a document-oriented DB that can store data in the form of a hierarchical structure.

In order to ensure requirement 3, the authors adopted Vue.js that is a framework for building UI for Web applications. The system dynamically generates questionnaires from the data in the DB via the Web API, based on the grades and learning activities selected by children. This makes it possible to reactively switch the display of the questionnaire items according to the operation without any webpage transition.

Figure 6 shows the architecture of the system based on the above design, and Figures 7 and 8 show the UI of the developed system. According to the schematic in Figure 6, when the user accesses the system, he/she selects the grade and experienced learning activity (Figure 7), and the questions and choices are displayed according to the input (Figure 8). The system obtains questions and choices via the API, with the grade and the learning activity as input parameters. The response data is saved in JSON format in MongoDB.

The definitions of the Web APIs for generating the questionnaire are shown in Table 1, 2 and example API responses for retrieving question and survey choices are shown in Tables 3, 4. From Table 1 and 2, each API is defined by five parameters: category (questionnaire generation, answer registration, and listing), API name, request parameters, response format, and description. The system 


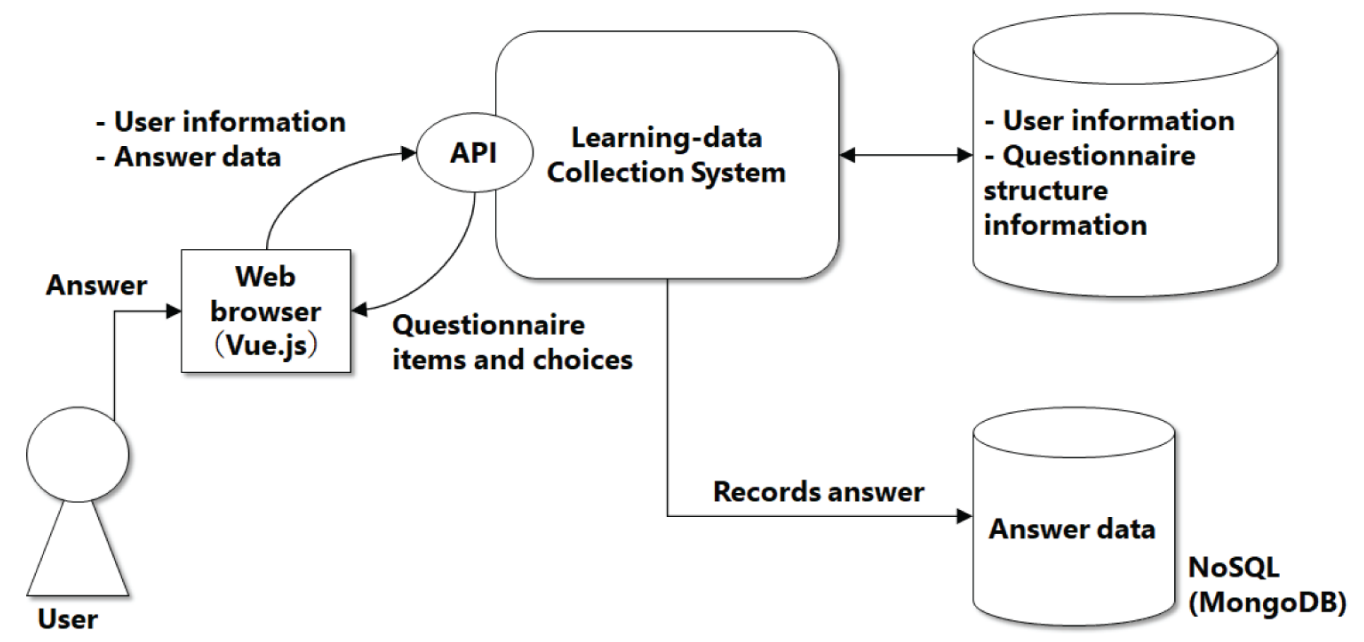

Figure 7. Web page of the collection system UI

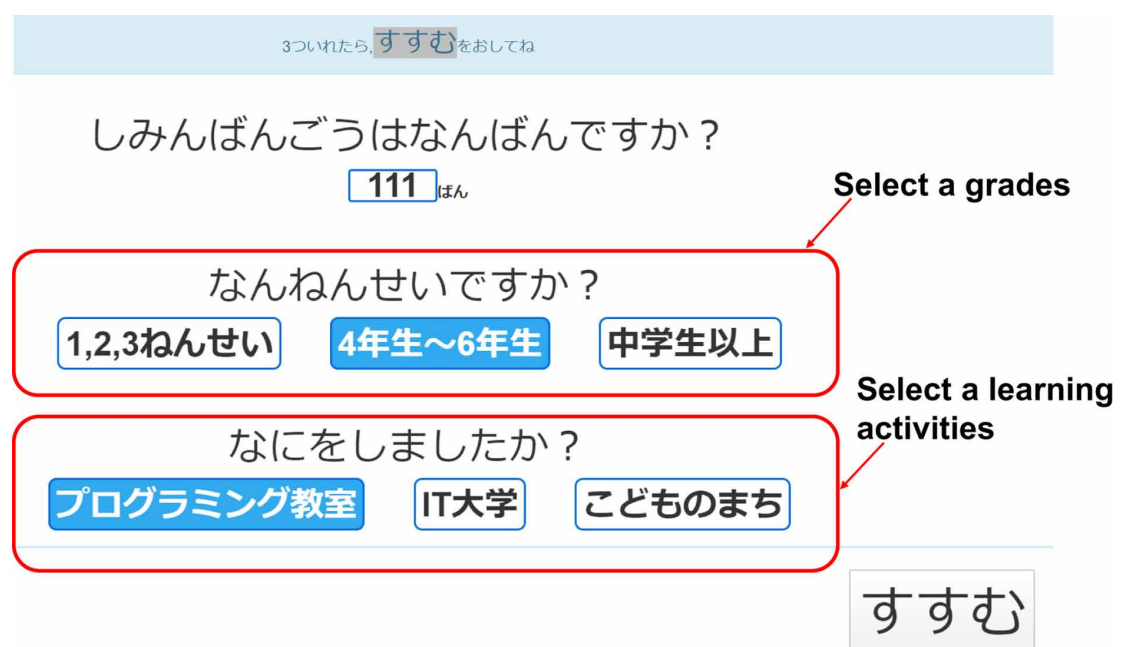

uses these APIs to dynamically generate questionnaires. Table 3 shows the example responses when the "question data" API (shown in Table 1) and the "question choices" API (shown in Table 4) are called. The "choice_no" in Table 4 shows the choice identification number described in the section, "Database Design". This enables the questionnaire to dynamically generate the questions linked to the child's developmental stage and learning activities, as shown in Figure 8.

\section{LEARNING ANALYTICS}

\section{Methodology}

To evaluate achievement of the research question, the correlation between learning frequency and self-directed learning will be investigated. It is assumed that students with more frequent learning 
Figure 8. Questionnaire generated based on grades and learning activities

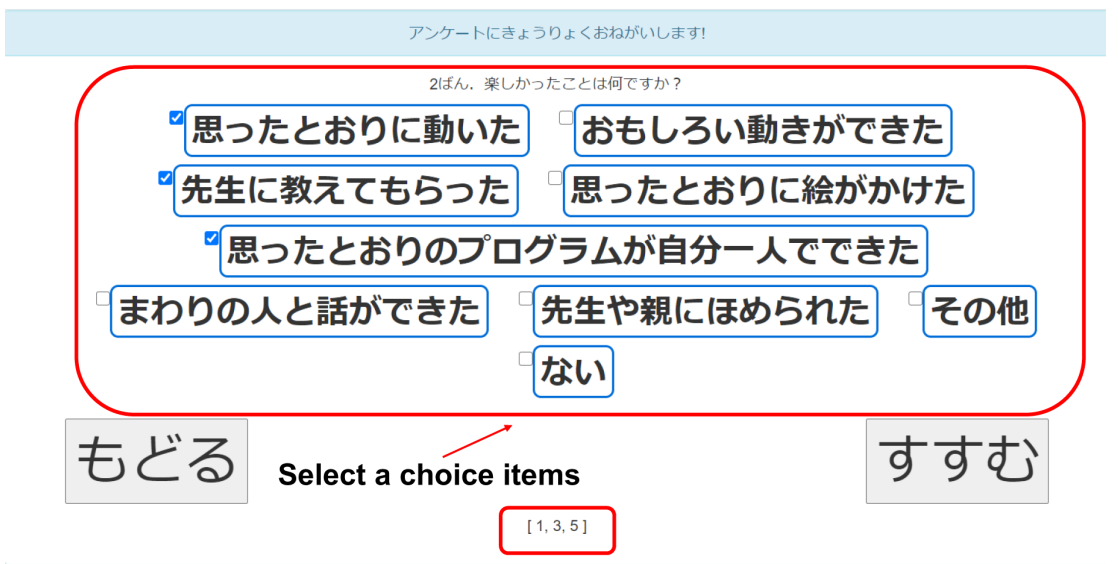

Choice number $[1,3,5]$

Table 1. Definitions of the Web APIs for the questionnaire (1)

\begin{tabular}{|c|c|c|c|c|c|}
\hline No. & Category & API Name & Request parameter & Response format & Description \\
\hline 1 & $\begin{array}{l}\text { Questionnaire } \\
\text { generation }\end{array}$ & question_data & $\begin{array}{l}\text { category_id: learning } \\
\text { category } \\
\text { grade_id: grade }\end{array}$ & $\begin{array}{l}\text { id: question ID } \\
\text { name: question } \\
\text { description } \\
\text { choice_flag: choice flag } \\
\text { - 0: single choice } \\
\text { - 1: multiple choice } \\
\text { - 2: free description (1 } \\
\text { line) } \\
\text { - 3: free description } \\
\text { (multiple lines) }\end{array}$ & $\begin{array}{l}\text { API to output } \\
\text { survey questions } \\
\text { based on category } \\
\text { and grade }\end{array}$ \\
\hline 2 & $\begin{array}{l}\text { Questionnaire } \\
\text { generation }\end{array}$ & $\begin{array}{l}\text { question_ } \\
\text { choices }\end{array}$ & $\begin{array}{l}\text { category_id: learning } \\
\text { category } \\
\text { grade_id: grade } \\
\text { question_no: question } \\
\text { number }\end{array}$ & $\begin{array}{l}\text { choice_no: choice } \\
\text { number } \\
\text { choice: choice } \\
\text { description } \\
\text { choice_id: choice ID }\end{array}$ & $\begin{array}{l}\text { API to output } \\
\text { choices based on } \\
\text { category, grade, } \\
\text { and question } \\
\text { number }\end{array}$ \\
\hline 3 & $\begin{array}{l}\text { Questionnaire } \\
\text { generation }\end{array}$ & $\begin{array}{l}\text { question_- } \\
\text { choice_data }\end{array}$ & $\begin{array}{l}\text { category_id: learning } \\
\text { category } \\
\text { grade_id: grade }\end{array}$ & $\begin{array}{l}\text { id: choice ID } \\
\text { question_id: question ID } \\
\text { choice_no: choice } \\
\text { number } \\
\text { choice: choice } \\
\text { description }\end{array}$ & $\begin{array}{l}\text { API to output } \\
\text { questions and } \\
\text { choices based on } \\
\text { category and grade }\end{array}$ \\
\hline
\end{tabular}

will have more complex and independent reasons for their achievement when their reflection after the learning. By recording the impression for self-reflection immediately after the learning, students can evaluate the specific achievement for their learning of the day. This is aimed to achieve students to keep their motivation for learning and support the achievement of self-directed learning.

\section{Classroom Operations}

The programming classrooms were held in Ichikawa and Urayasu city. There are 37 students since the classrooms have become operational in October 2016. After explaining the purpose of the study, the survey was conducted with total 35 participants in these classrooms whose parents gave their 
Table 2. Definitions of the Web APIs for the questionnaire (2)

\begin{tabular}{|c|c|c|c|c|c|}
\hline No. & Category & API Name & Request parameter & Response format & Description \\
\hline 1 & $\begin{array}{l}\text { Answer } \\
\text { registration }\end{array}$ & $\begin{array}{l}\text { course_user_ } \\
\text { data }\end{array}$ & $\begin{array}{l}\text { number: individual } \\
\text { number (local unique) } \\
\text { category_id: learnig } \\
\text { category } \\
\text { grade_id: grade }\end{array}$ & $\begin{array}{l}\text { record_number: record } \\
\text { number (global unique) } \\
\text { * rules: } \\
\text { YYYYMMDDCCGNNNN } \\
\text { - YYYYMMDD: date (8 } \\
\text { digits) } \\
\text { - CC: courses (2 digits) } \\
\text { - G: grade (1 digit) } \\
\text { - NNNN: individual number } \\
\text { (programming class: user } \\
\text { ID, IT university: reception } \\
\text { number, town of children: } \\
\text { citizen number, } 4 \text { digits) }\end{array}$ & $\begin{array}{l}\text { API to obtain } \\
\text { a number for } \\
\text { recording from a } \\
\text { citizen number }\end{array}$ \\
\hline 2 & $\begin{array}{l}\text { Answer } \\
\text { registration }\end{array}$ & mongo_post & $\begin{array}{l}\text { couse_user_id: course } \\
\text { user ID } \\
\text { answer: answer data } \\
\text { ans1: answer of question } 1 \\
\text { ans2: answer of question } 2 \\
\text {.. } \\
\text { ans9: answer of question } 9\end{array}$ & $\begin{array}{l}\text { same as on the left } * \text { echo } \\
\text { reply }\end{array}$ & $\begin{array}{l}\text { recording } \\
\text { questionnaire } \\
\text { results to DB }\end{array}$ \\
\hline 3 & Listing & prog_class_list & None & $\begin{array}{l}\text { class_id: class ID } \\
\text { class: class name } \\
\text { frequency: frequency }\end{array}$ & $\begin{array}{l}\text { API to output } \\
\text { a list of } \\
\text { programming } \\
\text { classes }\end{array}$ \\
\hline 4 & Listing & student_list & class_id: class ID & $\begin{array}{l}\text { student_id: student ID } \\
\text { name: name } \\
\text { grade_id: grade }\end{array}$ & $\begin{array}{l}\text { API to output a } \\
\text { list of students } \\
\text { for a given } \\
\text { programming } \\
\text { class ID }\end{array}$ \\
\hline
\end{tabular}

Table 3. Example of the questions as present in the DB

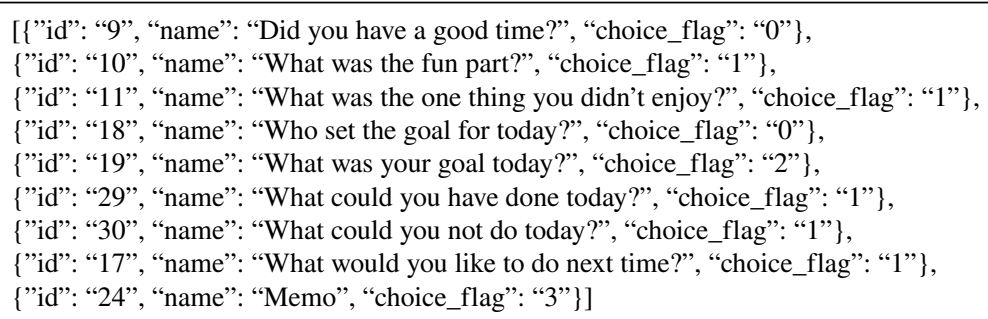

consent for an 8-month period from June 8, 2019 to February 8, 2020. However, in September 2019, all the classrooms were cancelled due to typhoons and unavailability of a lecturer. Six classes were held in Myoden, seven in Minami-Gyotoku, and another six classes in Shin-Urayasu every month.

\section{Results and Discussions}

The records of the learning activities of each classroom are shown in Table 5. It can be seen from Table 5 that a total of 254 records of learning activities are obtained: 104 for weekly courses, 22 for biweekly courses, and 128 for monthly courses at three locations. Students of the weekly and biweekly courses have more opportunities for reflection in comparison with monthly course and are 
Table 4. Example of the survey choices as present in the DB

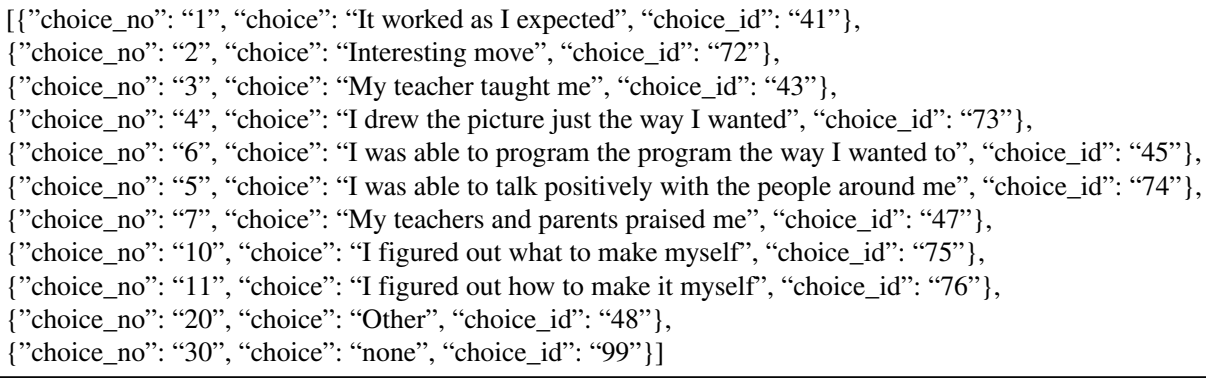

Table 5. Records of learning activities for each classroom

\begin{tabular}{|c|c|c|c|c|c|}
\hline \multirow{2}{*}{ Place } & \multirow{2}{*}{ Course } & \multicolumn{4}{|c|}{ Number of learning activities } \\
\hline & & Avg & Max & Min & Total \\
\hline \multirow{3}{*}{ Myoden } & Weekly & 20.8 & 25 & 17 & 104 \\
\hline & Biweekly & 11 & 12 & 10 & 22 \\
\hline & Monthly & 3.56 & 6 & 2 & 32 \\
\hline Minami-Gyotoku & Monthly & 6.09 & 6 & 2 & 67 \\
\hline \multirow[t]{2}{*}{ Shin-Urayasu } & Monthly & 3.63 & 5 & 1 & 29 \\
\hline & & & & & 254 \\
\hline
\end{tabular}

more likely to be able to observe the continued-learning effects in the classroom. Further, since the frequency of the monthly course is low, if a student is continuously absent due to illness, event or some other reason, a period of two or three months may be vacated from the previous class, making it difficult to continuously observe the effects of the class.

The percentage of students who responded, "I enjoyed it/so-so much" and "I was able to do it/ mostly able to do it" for each developmental stage were $96.9 \%$ and $89.8 \%$ respectively. The percentage of students who reported that they enjoyed and were able to do so was lower in the upper grades than in the lower grades. On the contrary, since most of the students reported that they enjoyed programming, it was not possible to find a relationship between whether they had enjoyed and the reasons. Therefore, the validity of the questionnaire for analyzing the children's orientation was not confirmed, and the questionnaire itself required reconsideration.

Table 6 shows the responses to the questions of whether they enjoyed it and why, whether they were able to perform the task and why, and what they wanted to do next. The authors focus on the later elementary grades that contribute to the largest number of responses and analyze the trend. From Table 6, it can be seen that whether or not one is able to observe the progress one intended for or not, and whether or not one is able to do what one needs to do, has a significant impact on whether or not the person enjoyed it. Accordingly, many students reported that it was "not fun" when the intended progress could not be observed. In terms of what they were able to do, they were able to act independently against to their issue, such as devising the program, that is, thinking of original movements about character animation and new feature function about game judgement. It was confirmed that the learning frequency would have an impact on deep reflection that contributes to self-directed learning in programming education. 
Table 6. Analysis of questionnaire responses (late elementary grades)

\begin{tabular}{|l|l|l|}
\hline \multicolumn{1}{|c|}{ Questions } & \multicolumn{1}{|c|}{ Responses } & \multicolumn{1}{c|}{ Answers } \\
\hline \multirow{4}{*}{ Why it was fun? } & That was an interesting move & 78 \\
\cline { 2 - 3 } & My teacher taught me & 70 \\
\cline { 2 - 3 } & It worked just like I thought it would & 65 \\
\hline \multirow{4}{*}{ Why it wasn't fun? } & Nothing & 121 \\
\cline { 2 - 3 } & It didn't work the way I thought it would & 44 \\
\cline { 2 - 3 } & It didn't paint the way I wanted it to & 15 \\
\hline \multirow{5}{*}{ What you couldn't do? } & I could devise a program & 71 \\
\cline { 2 - 3 } & I thought about how I could do it & 70 \\
\cline { 2 - 3 } & Now I know what my teacher taught me & 42 \\
\hline \multirow{5}{*}{ What do you want to do next? } & I couldn't finish what I was doing & 93 \\
\cline { 2 - 3 } & Nothing & 65 \\
\cline { 2 - 3 } & I didn't think about how I could do it & 14 \\
\cline { 2 - 3 } & I want to finish what I'm doing & 117 \\
\hline & I want to figure out for myself how to dit & 96 \\
\hline
\end{tabular}

Students and teachers can provide feedback on what they are able or unable to do when reviewing their learning, in addition to indicating the choices. At the beginning of the survey, for students who have experienced significant improvement in their programming skills, unspecific responses such as, "I solved the problem" and "I found the cause of the problem," were common. However, in the latter half of the survey, specific responses such as "I was able to cancel the message", "The content of the associative array is strange", and "I want to make it possible to display in real time" were more common. As they are able to learn more deeply, they are able to clearly distinguish between what they know and what they don't know with respect to the subject being learned, and they are able to realize the acquisition of computational thinking. On the contrary, in the case of students who do not make much progress in their studies, the responses observed at each review are, "I didn't finish what I had to do" or "I didn't understand what the teacher had taught me." However, there are still many problems in independent learning.

Table 7 shows the correlation coefficients between the reasons for having fun and what one wants to do next, and Table 8 shows the correlation coefficients between the reasons for what did it and what one wants to do next. Since most of the students enjoyed and were able to do it, there was no correlation for most of the responses.

From Table 7, almost responses are not correlated with "whether they have enjoyed it" regardless of the learning frequency. In the weekly class, there was a weak negative correlation (-0.232) between the responses to "whether they have enjoyed it" and "It didn't work the way I thought it would" of "Why was NOT it fun?", and there was a weak positive correlation $(0.200)$ between the responses to "whether they have enjoyed it" and "I need to finish what I started" of "What I want to do NEXT?". In the biweekly class, since all the responses were "they have enjoyed it", there was a no correlation (N/A). As a question in survey, asking "whether they have enjoyed it" was not an indicator to classify the children's orientation. 
Table 7. Correlation coefficient for fun

\begin{tabular}{|c|c|c|c|c|}
\hline Questions & Responses & Weekly & Biweekly & Monthly \\
\hline \multirow{9}{*}{ Why was it fun? } & It worked just like I thought it would. & 0.181 & N/A & 0.002 \\
\hline & Interesting move. & -0.139 & N/A & -0.086 \\
\hline & My teacher told me. & 0.120 & N/A & 0.113 \\
\hline & The picture painted just the way I wanted it. & 0.200 & N/A & -0.131 \\
\hline & $\begin{array}{l}\text { I was able to do the program the way I thought it } \\
\text { would be done, all by myself. }\end{array}$ & 0.028 & N/A & 0.082 \\
\hline & I could talk to people around me. & -0.070 & N/A & 0.016 \\
\hline & My teachers and my parents complimented me. & N/A & N/A & 0.046 \\
\hline & I figured out what to make myself. & N/A & N/A & N/A \\
\hline & I figured out how to make it myself. & N/A & N/A & N/A \\
\hline \multirow{6}{*}{ Why was NOT it fun? } & It didn't work the way I thought it would. & -0.232 & N/A & -0.052 \\
\hline & I wasn't quite sure what I'd done. & -0.094 & N/A & N/A \\
\hline & The painting didn't come out the way I wanted it to. & -0.185 & N/A & 0.016 \\
\hline & I was just doing what the doctor told me to do. & -0.094 & N/A & N/A \\
\hline & I didn't get to talk much with the people around me. & 0.004 & N/A & -0.200 \\
\hline & Teachers and parents made me do it. & 0.064 & N/A & N/A \\
\hline \multirow{6}{*}{$\begin{array}{l}\text { What I want to do } \\
\text { NEXT? }\end{array}$} & I need to finish what I started. & 0.214 & N/A & 0.072 \\
\hline & I want to get creative with the program. & 0.036 & N/A & 0.072 \\
\hline & I want to figure out for myself how to do it. & 0.003 & N/A & 0.089 \\
\hline & I want to draw a picture of my own design. & -0.114 & N/A & -0.131 \\
\hline & $\begin{array}{l}\text { I want to be able to explain what I've created to } \\
\text { others. }\end{array}$ & -0.185 & N/A & 0.046 \\
\hline & $\begin{array}{l}\text { I want to be able to understand what my teacher } \\
\text { taught me. }\end{array}$ & -0.073 & N/A & 0.046 \\
\hline
\end{tabular}

From Table 8, there was a difference in the correlation between the responses of "What did you do?" by the learning frequency. All classes had a weak positive correlation (over 0.3) between the responses to "whether they were able to do it" and "I've done all I need to do". In addition, biweekly class had a correlation at "I could have devised a program" $(0.263)$ too, and in weekly class had a correlation at "I've been thinking about how to do it" $(0.236)$ and "I drew my own picture" $(0.272)$ in addition to the responses in biweekly class. From the above, it was confirmed that the more frequent learning, the deeper reflection was possible to promote more self-directed learning. However, feedback to the students with less frequent learning is an issue should be solved. Especially, in the monthly classes, it was confirmed that the students' feeling of accomplishment was affected only by completing the assigned learning tasks suggested by teachers. In fact, the students often focused only on completing the tasks, and then it is difficult for the students to focus on what they really want to do or what they should do. Therefore, the authors will develop a feedback system designed to promote long-term goal setting based on deeper reflection considering the results of this survey in the future. Concretely, after confirming their previous reflections, the system will be provided that the students will select one of the learning tasks selected by other students with similar orientation, and they can 
Table 8. Correlation coefficient for did it

\begin{tabular}{|c|c|c|c|c|}
\hline Questions & Responses & Weekly & Biweekly & Monthly \\
\hline \multirow{6}{*}{ What did you do? } & I've done all we need to do. & 0.314 & 0.451 & 0.318 \\
\hline & I could have devised a program. & 0.280 & 0.263 & -0.079 \\
\hline & I've been thinking about how to do it. & 0.236 & -0.203 & -0.032 \\
\hline & I drew my own picture. & 0.272 & 0.182 & 0.032 \\
\hline & I could explain to others what I had created. & -0.036 & N/A & -0.038 \\
\hline & I understand what the doctor taught me. & 0.095 & 0.197 & -0.093 \\
\hline \multirow{5}{*}{$\begin{array}{l}\text { What did NOT you } \\
\text { do? }\end{array}$} & I didn't finish what I was doing. & -0.009 & 0.128 & -0.259 \\
\hline & I didn't think about how to do it. & 0.000 & 0.000 & 0.000 \\
\hline & I couldn't draw a picture of my own design. & 0.006 & N/A & -0.370 \\
\hline & I couldn't explain to others what I had created. & -0.055 & N/A & 0.129 \\
\hline & $\begin{array}{l}\text { I didn't understand what the teacher was teaching } \\
\text { me. }\end{array}$ & -0.044 & N/A & -0.143 \\
\hline \multirow{6}{*}{$\begin{array}{l}\text { What I want to do } \\
\text { NEXT? }\end{array}$} & I need to finish what I started. & 0.129 & -0.120 & -0.160 \\
\hline & I want to get creative with the program. & 0.014 & -0.342 & 0.140 \\
\hline & I want to figure out for myself how to do it. & -0.068 & 0.120 & -0.057 \\
\hline & I want to draw a picture of my own design. & 0.118 & N/A & 0.096 \\
\hline & $\begin{array}{l}\text { I want to be able to explain what I've created to } \\
\text { others. }\end{array}$ & -0.113 & N/A & -0.143 \\
\hline & $\begin{array}{l}\text { I want to be able to understand what my teacher } \\
\text { taught me. }\end{array}$ & -0.081 & N/A & -0.143 \\
\hline
\end{tabular}

choose their own tasks and strategies for their solutions. In the feedback system, simple data mining algorithm will be adopted to clustering of the behavioral traits and interests. And then, personalized feedback system for learners will be designed referring to Hdioud et al., (2017). In their research, various recommender systems based on several strategies such as attention-based, contention-based, and personalized, etc. were surveyed, and a multi-criteria recommender method using integrated approach with correlation coefficient and standard deviation to minimize user effort and maximize satisfaction was proposed (Hdioud et al., 2017).

\section{CONCLUSION}

In this study, the authors developed a learning-data collection system that would collect the data corresponding to the developmental stages and learning activities of children to understand their behavioral traits and interests. This system would contribute to the independent selection of learning tasks by collecting and analyzing the learning records of the children from the programming classroom. After each class, the impressions, achievements, and expectations for the next class were recorded. The results showed that the students who actively worked on the programming tasks gradually developed computational thinking.

In the future, the authors plan to develop a system that determines the similarity between the behavioral traits and interests of children by data mining the collected learning activities, and presents the learning tasks that children who have high similarity in orientation to themselves have worked on when selecting learning tasks. As the students' progress through the developmental stages, the system 
will be able to recommend more accurate assignments, and the children will be able to focus on the specific field of their choice across the wide range of options and deepen their understanding of that field. In addition to the level of satisfaction with the tasks recommended by the system, the authors also survey the change in awareness of whether the students are able to decide their own study tasks.

\section{ACKNOWLEDGMENT}

This work was supported by the JSPS KAKENHI [grant number JP19K02982]. We would like to thank Editage (www.editage.com) for English language editing. 


\section{REFERENCES}

Covey, S. R. (1989). The 7 Habits of Highly Effective People. Free Press.

Hdioud, F., Frikh, B., Ouhbi, B., \& Khalil, I. (2017). Multi-Criteria Recommender Systems: A Survey and a Method to Learn New User's Profile. International Journal of Mobile Computing and Multimedia Communications, 8(4), 20-48. doi:10.4018/JJMCMC.2017100102

Kawano, Y. (2014). Chiba-shi hanamigawa-ku miryokuhasshin project "Hanamigawa.com!" no unyoutaiseidukuri to kongo no tenbou [Operational Structure and Action Plan about Community Branding Project "Hanamigawa.com!" for Hanamigawa-ku in Chiba-city]. Tokyo University of Information Sciences, Departmental Bulletin Paper, 18(1), 35-44.

Kawano, Y., \& Kawano, Y. (2018). Programming kyoshitsu Candy no unei to kadai [Management and Issues of Programming School Candy]. IEICE Technical Report, Cyber world, 38.

Kawano, Y., \& Kawano, Y. (2019). Kodomotachi no syutaiteki-na-manabi wo sokushin-suru gakusyu-shien system no kentou [Consideration of the e-learning System for Children to Promote Proactive Learning]. Japanese Society for Information and Systems in Education (JSiSE), Technical Report, 2018(6).

Kawano, Y., \& Kawano, Y. (2020). A Proposal of Children Learning System to Promote Self-directed Choosing of Learning Tasks and Analysis of Learning Data in a Programming Classroom. The 23rd International Conference on Network-Based Information Systems (NBiS-2020).

Kawano, Y., \& Shingyoji, N. (2017). Evaluation of Active Learning Method for Students by Community Activities with Children. 22nd International Symposium on Artificial Life and Robotics (AROB 22nd).

Matsuda, T. (2018). Teigakunen programming-kyoiku no hitsuzensei to sono-jissai [Necessity of low grade programming education and in fact -through utilization of Cutlery Apps]. Japan Society of Digital Textbook, 7.

Ministry of Education, Culture, Sports, Science and Technology (MEXT). (2015). Shogaikoku ni-okeru programming-kyoiku ni-kansuru tyousakenkyu [Information Education Leadership Improvement Support Project (Research on Programming Education in Other Countries)]. Retrieved May 31, 2020 from https://www.mext. go.jp/a_menu/shotou/zyouhou/detail/_icsFiles/afieldfile/2018/08/10/programming_syogaikoku_houkokusyo.pdf

Mistry of Education, Culture, Sports, Science and Technology (MEXT). (2016). Shogakkou-dankai ni-okeru programming-kyoiku no arikata ni-tsuite [Programming Education at the Elementary School Level (Summary of Discussion)]. Retrieved May 31, 2020 from https://www.mext.go.jp/b_menu/shingi/chousa/shotou/122/ attach/1372525.htm

Shibuya, K. (2018). Sougouteki-na-gakusyu-no-jikan ni-okeru programming-kyoiku [Programming Education in Elementary School Integrated Learning Time]. Retrieved May 31, 2020 from https://miraino-manabi.jp/ content $/ 260$

Takahashi, K. (2010). Kodomotachi ga jichiteki-katsudou wo okonau-sugata wo motomete: "Nanatsu-no-syukan" wo ishiki-sita torikumi wo hashira ni-shite [Looking for children to be autonomous in their activities: Focusing on the "Seven Habits"], Center for Educational Research and Development, Joetsu University of Education. Departmental Bulletin Paper, 20, 217-222.

Tamura, M. (2017). Daigaku - chiiki-renkei ni-yoru "Wakaba kodomo-no-machi CBT" no torikumi [A Report of "WAKABA-CBT" Project by Partnership Between University and Regional Area], Uekusa Gakuen University. Departmental Bulletin Paper, 18, 1-7.

Toyoda, M. (2017). Syogakkou programming-jugyo no suishin ni-okeru jissenjo-no-kadai [Report on considerations for promoting programming class at elementary school], Graduate School of Teacher Education Wakayama University bulletin of Course Specializing in Professional Development in Education, 2, 83-90.

United Nations, Department of Economic and Social Affairs, Population Division. (2017). World Population Prospects: The 2017 Revision, Key Findings and Advance Tables. ESA/P/WP/248.

Ushiroyama, E. (2008). Kodomo no syutaisei wo sodateru fukushi-kyoiku - chiiki-no-renkei no-arikata [Welfare education that fosters children's autonomy]. Bulletin of Tokai Gakuin University, 2, 43-46. 